\title{
Foreign Bodies in ENT from Peripheral Health Center of Bamako (Mali)
}

\author{
Youssouf Sidibé ${ }^{1}$, Djibril Samaké ${ }^{2,}$ *, Adama Togola ${ }^{3}$, Yatemelou Dara ${ }^{1}$, Sinaly Thiocary ${ }^{4}$,

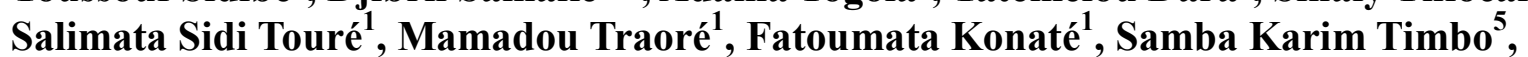 \\ Mohamed Amadou Kéïta ${ }^{5}$, Alhousseini Ag Mohamed ${ }^{5}$
}

${ }^{1}$ ENT (Ear, Nose, Throat) and Head and Neck Surgery (HNS) Department University Hospital Center Mother-Child "The Luxembourg", Bamako, Mali

${ }^{2}$ ENT (Ear, Nose, Throat) and Head and Neck Surgery (HNS) Department, Commune V Reference Health Center, Bamako, Mali

${ }^{3}$ ENT (Ear, Nose, Throat) and Head and Neck Surgery (HNS) Department, University Hospital Center "Mali Hospital ", Bamako, Mali

${ }^{4}$ Department of Stomatology and Maxillofacial Surgery, University Hospital Center "National Odonto-Stomatology Center", Bamako, Mali

${ }^{5}$ ENT (Ear, Nose, Throat) and Head and Neck Surgery (HNS) Department, University Hospital Center -Gabriel Touré, Bamako, Mali

\author{
Email address: \\ samakedjibi@yahoo.fr (D. Samaké) \\ ${ }^{*}$ Corresponding author
}

\section{To cite this article:}

Youssouf Sidibé, Djibril Samaké, Adama Togolaz, Yatemelou Dara, Sinaly Thiocary, Salimata Sidi Touré, Mamadou Traoré, Fatoumata Konaté, Samba Karim Timbo, Mohamed Amadou Kéita, Alhousseini Ag Mohamed. Foreign Bodies in ENT from Peripheral Health Center of Bamako (Mali). International Journal of Otorhinolaryngology. Vol. 7, No. 1, 2021, pp. 1-5. doi: 10.11648/j.ijo.20210701.11

Received: March 9, 2021; Accepted: March 22, 2021; Published: April 13, 2021

\begin{abstract}
Foreign bodies in ENT (Ear, Nose, Throat) often cause emergencies following their appearance, their location and can be life-threatening. The aim of this work was to study the epidemiological and clinical profile of foreign bodies in ENT in a peripheral health center of Bamako. This was a cross-sectional study carried out in the ENT department of the Reference Health Center of Commune V of Bamako from January 2018 to December 2018. In our current study, the frequency of foreign bodies in ENT was 1.47\% (68 cases) detected from 4630 medical consultations. The male / female ratio was 1.12 , ie 36 men and 32 women. The 0 to 5 age group represented $42.6 \%$. The average age was 15 years with extremes of 10 months and 76 years. We identified $58.9 \%$ of foreign bodies from ear, $32.4 \%$ from the nasal cavity; those of the bronchi, esophagus and pharynx each accounted for $2.9 \%$. Cotton represented $19.1 \%$, pebbles and food foreign bodies (13.2\% each); and a button cell battery case. Foreign bodies are most often seen in children in ENT. Their natures are diverse. It can be an emergency. Complications can be fatal. Prevention intervention must be taken. The adequacy of the technical platform taking care that important ENT aspect is essential.
\end{abstract}

Keywords: Foreign Body, Emergency, Child, ENT

\section{Introduction}

Foreign bodies are common in ear, nose and throat (ENT) consultations $[1,2]$. They often cause health emergencies by their appearance (sharp, pointed), their location (nasal cavity, larynx) or their nature (button cell battery) and can quickly be life threatening. Neglected or old foreign bodies undetected can cause complications (traumatic laryngitis, suppurative mediastinitis, dilation of the bronchi) [1, 3]. Publications on this subject are frequent. However, they are quite often related to precise anatomical sites of the ENT sphere (nasal foreign body, laryngotracheo-bronchial foreign body, foreign body of the esophagus of adults, foreign body of the aero-digestive tract of the child) [1, 3-6]. To ensure better care and prevention, the analysis of global local epidemiological data is necessary for health areas. The Reference Health Center of commune V is by its geographical location at the forefront of a large part of the Bamako population and its surroundings. This work was a descriptive study, in the form of part of the annual report of the otolaryngological consultation at the Reference Health Center of Commune V (CSRéf CV) in the district of Bamako 
(Mali).

\section{Objectives}

1) Determine the frequency of foreign bodies in ENT

2) Study the socio-demographic characteristics of patients

3) To profile the different locations and the nature of the foreign bodies detected

4) Report the provided treatments

\section{Materials and Method}

The study was carried out in the ENT (Ear, Nose, Throat) and Head and Neck Surgery (HNS) department of the Reference Health Center of Commune V (CSRéf CV) of the District of Bamako in Mali. This was a cross-sectional study conducted over one year from January 2018 to December 2018 on patients that visited the ENT-HNS center for medical consultation. The inclusion criteria were any patient who had came for medical consultation and in whom a foreign body had been diagnosed. Patients who came for a medical consultation for another known ENT pathology, those treated by other services or already reaching the stage of complication after the extraction of foreign bodies and incomplete files were not included. The variables studied were: sex, age, location of foreign bodies, reason of the medical consultation, nature of the foreign bodies, treatment.
The information obtained was mentioned on an anonymous individual data collection sheet on which the variables to be studied appeared. Ethically, confidentiality and the informed consent of patients were respected. Statistical analysis was done by SPSS 22.0 software. The Chi2 statistical test was used.

\section{Results}

\subsection{Frequency}

With 68 recorded cases, the frequency of foreign bodies in ENT detected in this study was $1.47 \%$ (68 cases) with 36 men (52.9\%) and 32 women (47.1\%) all from 4630 medical consultations. The male / female ratio was 1.12 (Table 1).

\subsection{Sociodemographic Aspects}

The 0 -to-5-years age group (Table 2) represented $42.6 \%$ of cases followed by the 5 to 10 year group $19.1 \%$ of cases. The average age was 15 years with extremes of 10 months and 76 years. Children under 15 were $72.05 \%$ of the series and the rest $(27.95 \%)$ were over 15 years old. Preschool children accounted for $41.2 \%$; pupils and students $32.3 \%$ and the rest (26.5\%) were active adults. Residents of commune V accounted for $92.6 \%$ of cases and the others $(7.4 \%)$ came from Kati; of commune IV and commune VI.

Table 1. Distribution of foreign bodies positive patients following their sex and the location of the foreign body.

\begin{tabular}{lllllll}
\hline Foreign body postive patients Sex & CEN & CEO & CEP & CEOE & CEB & Total \\
\hline Male & $07(31.81 \%)$ & $25(62.5 \%)$ & $01(50 \%)$ & $01(50 \%)$ & $02(100 \%)$ & $36(52.94 \%)$ \\
Female & $15(68.18 \%)$ & $15(37.5 \%)$ & $01(50 \%)$ & $01(50 \%)$ & $00(0 \%)$ & $32(47.05 \%)$ \\
Total & $22(100 \%)$ & $40(100 \%)$ & $02(100 \%)$ & $02(100 \%)$ & $02(100 \%)$ & $68(100 \%)$ \\
\hline
\end{tabular}

CEN: Nasal foreign body. CEO: Foreign body in the ear. CEOE: Foreign body of the esophagus. CEB: Bronchial foreign body. CEP: Foreign body of the pharynx.

Foreign bodies from the nose were more common in girls $(68.18 \%)$, while they were more common in the ear in boys, $\mathrm{p}=0.0206$. For the other locations of foreign bodies, girls and boys were no significant difference $(\mathrm{p}>0.05)$.

Table 2. Distribution of foreign bodies positive patients following their age depending on the nature of the foreign body.

\begin{tabular}{|c|c|c|c|c|c|c|}
\hline foreign bodies positive patients age (year) & CEN & CEO & CEP & CEOE & CEB & Total \\
\hline$[0-5]$ & $15(68.18 \%)$ & $10(25 \%)$ & $00(0 \%)$ & $02(100 \%)$ & $02(100 \%)$ & $29(42.64 \%)$ \\
\hline [5-10] & $05(22.72 \%)$ & $08(20 \%)$ & $00(0 \%)$ & $00(0 \%)$ & $00(0 \%)$ & $13(19.11 \%)$ \\
\hline$[10-15]$ & $01(4.54 \%)$ & $06(15 \%)$ & $00(0 \%)$ & $00(0 \%)$ & $00(0 \%)$ & $07(10.29 \%)$ \\
\hline$[15-20]$ & $00(0 \%)$ & $01(2.5 \%)$ & $00(0 \%)$ & $00(0 \%)$ & $00(0 \%)$ & $01(1.47 \%)$ \\
\hline [20-25] & $00(0 \%)$ & $02(5 \%)$ & $02(100 \%)$ & $00(0 \%)$ & $00(0 \%)$ & $04(5.88 \%)$ \\
\hline [25-30] & $00(0 \%)$ & $01(2.5 \%)$ & $00(0 \%)$ & $00(0 \%)$ & $00(0 \%)$ & $01(1.47 \%)$ \\
\hline [30-35] & $01(4.54 \%)$ & $02(5 \%)$ & $00(0 \%)$ & $00(0 \%)$ & $00(0 \%)$ & $03(4.41 \%)$ \\
\hline$[35-40]$ & $00(0 \%)$ & $05(12.5 \%)$ & $00(0 \%)$ & $00(0 \%)$ & $00(0 \%)$ & $05(7.35 \%)$ \\
\hline [40 et plus] & $00(0 \%)$ & $05(12.5 \%)$ & $00(0 \%)$ & $00(0 \%)$ & $00(0 \%)$ & $05(7.35 \%)$ \\
\hline Total & $22(100 \%)$ & $40(100 \%)$ & $02(100 \%)$ & $02(100 \%)$ & $02(100 \%)$ & $68(100 \%)$ \\
\hline
\end{tabular}

CEN: Nasal foreign body. CEO: Foreign body in the ear. CEOE: Foreign body of the esophagus. CEB: Bronchial foreign body. CEP: Foreign body of the pharynx.

1) In children from $0-5$ years old:

2) Foreign bodies were more common $(68.18 \%)$ in the nose than in the ears $(25 \%)$. $\mathrm{p}=0.0009$.

3 ) They were more common in the esophagus $(100 \%)$ than in the ear $(25 \%)$. $\mathrm{p}=0.0219$.
4) They were seen in the esophagus $(100 \%)$ and in the bronchi $(100 \%)$ while they were absent in the pharynx. $\mathrm{p}=0.0455$.

5) In patients aged 20-25: All pharyngeal foreign bodies were present $(100 \%)$ while there were no bronchial or 
esophageal cases. $\mathrm{p}=0.0455$.

6) In the other cases there were no statistical significance differences. $\mathrm{p}>0.05$.

\subsection{Clinical Aspects}

The main reasons for medical consultation were otalgia $33.8 \%$ for otological locations; nasal obstruction $14.6 \%$ for nasals and dyspnea $4.4 \%$ for pharyngolaryngeal and bronchial locations. Penetration syndrome was noted on interrogation for bronchial foreign bodies. Dysphagia and vomiting have been the main symptom of foreign objects in the esophagus. The circumstances of occurrence were gambling in 57.4\%; the meal and accidentally for the rest of the cases $(42.6 \%)$. There was no specific pathological history reported. The consultation time varied from 24 hours to one week in $47.1 \%$ of cases following the accident. In $22 \%$, the consultation took place within 24 hours of the accident. The rest $(30.9 \%)$ took more than a week. The different locations are shown in Tables 1 and 2. The localization was otological (58.83\%), nasal (32.35\%), bronchial (2.94\%), and oesophageal $(2.94 \%)$. The nature of the foreign bodies is recorded in Table 3. It was inorganic in 52.94\%, food organic in $13.23 \%$, plant organic in $23.53 \%$, and insects in $10.3 \%$.

Table 3. Distribution according to the nature of the foreign bodies.

\begin{tabular}{lll}
\hline Nature & Effective & Percentage (\%) \\
\hline Cotton & 13 & 19.1 \\
Sponge & 08 & 11.8 \\
Pebble & 09 & 13.2 \\
Insect & 07 & 10.3 \\
Pearl & 07 & 10.3 \\
Food & 09 & 13.2 \\
rubber & 05 & 7.4 \\
Piece of chalk & 03 & 4.4 \\
Piece of wood & 02 & 2.9 \\
piece of money & 02 & 2.9 \\
piece of paper & 01 & 1.5 \\
lump of coal & 01 & 1.5 \\
button cell battery & 01 & 1.5 \\
Total & 68 & 100 \\
\hline
\end{tabular}

\subsection{Therapeutics Aspects}

Ear washing was performed in $57.4 \%$ of the cases; chairside forceps extraction in $36.8 \%$. Esophagoscopy and bronchoscopy each $2.9 \%$ under general anesthesia.

\section{Discussion}

The limits of this work are follow:

1) The work environment was characterized by the lack of adequate equipment and infrastructure for ENT. All of the political choices are focused primarily on gynecology and obstetrics. The staff of the unit consists of a Doctor with four medical assistants. This state of affairs often obliges us to refer certain patients to structures that are better equipped but also well equipped with human resources for optimal care needs. Due to the insufficiency or absence of data on some patients, they were not included in this work. Further work on the referred cases can give a precise estimate of all cases in terms of frequency in our structure.

2) The country's under-medicalization, linked in part to a lack of infrastructure and a certain degree of obscurantism of the families, contributes to a long consultation period. In some cases, treatment is initially provided by traditional therapists or often by health workers who are ill-informed on the issue. The risks of complications, which are often fatal, even before patients arrive at an appropriate health facility are real. Further study from this angle could be of interest. Information, education and communication with parents, patients and even with non-ENT health personnel is essential.

3) The size of the participants was small (68) leading weaker statistical significance. A longer study period (between 5 or 10 years) could help to have a larger participant size.

\subsection{Frequency}

Foreign bodies in ENT represented $1.47 \%$ of all medical consultations in the ENT unit of the CSREF CV. This result is significantly lower as compared to that of a previous study in the same unit conducted in 2017. That 2017 study found that foreign bodies represented $4 \%$ of ENT consultations [7]. Previous 2017 study is also in agreement with study conducted by Njiffou [8] where ENT foreign bodies represented $2.58 \%$ of consultations in the ENT department at the Laquinitinie hospital in Douala (Cameroon). Ouoba found that foreign bodies occupied a notable place in emergencies, ie $33.07 \%$ at Ouagadougou hospital [9].

\subsection{Sociodemographic Aspects}

The majority of patients were $41.2 \%$ preschool children, followed by $32.3 \%$ school and university students. These accidents occur in the vast majority of cases in children under 6 years like in our study where we found that $42.6 \%$ were under 5 years old. The youngest patient was 10 months old and $72.05 \%$ of patients were under 15 years old [10].

The male sex was predominant $(52.9 \%)$ with a sex ratio of 1.2. Sex ratio from most authors was similar; 1.8 from Kacouchia [3] and 1.5 from Khaoula [1]. This could be explained by the fact that little boys, in general, have a more developed instinct for discovery and are more rowdy than little girls of the same age. Indeed, it is well known that childhood is a period of exploration of oneself and of one's environment. And that the little boy is more turbulent and reckless than the little girl [11].

\subsection{Clinical Aspects}

The foreign body is generally accidental occurring during play or meals and the nature of the object dependent on those placed at the disposal of the child in his immediate environment [12]. It usually occurs in people with normal development. It can be favored by a particular ground: 
mental retardation, trisomy or any other psychomotor disability [1]. In our study, 57.4\% occurred during gambling and we did not record any particular pathological history. This result is close to that of Diallo et al. in Guinea, which found that in the majority of cases $(54.17 \%)$, foreign bodies are introduced during games [2].

In our study, more than half of the cases $(58.9 \%)$, the foreign bodies were located in the external auditory canal distributed between 25 boys and 15 girls, with an average age of 20 years and extremes of 1 years and 76 years old; results comparable to certain publications where atrial localization predominated at $52.23 \%$ [13]; 57.8\% [14]; and 64.7\% [2]. Other studies have found other results. In this case those carried out by Khaoula [1] and Kharoubi [5] who found that esophageal foreign bodies represented the highest incidence at $47.53 \%$ and $51.02 \%$ respectively. We found 22 cases of nasal foreign bodies representing $32.4 \%$ of cases divided into 7 boys and 15 girls. Their average age was $4+/-2.5$ years with extremes ranging from 18 months to 14 years. The predominance of atrial and nasal foreign bodies is not surprising, as young children are by nature curious and enjoy exploring the openings of their bodies, especially the nose and ears [15].

Almost half of the patients $(47.1 \%)$ were seen in consultation during the first week beyond the 24th hour following the notion of the foreign body. Early consultations in less than 24 hours only accounted for $22 \%$. The predominance $(78 \%)$ of delayed consultations could be explained by the obscurantism of the parents and often by a certain degree of inattention from the parents. A study of parental attitudes, behavior and knowledge of foreign bodies could support this claim. The most common occurrence of the accident occurred during play. In the absence of improper handling during a failed extraction attempt, atrial seat foreign bodies are not very symptomatic [12]. But over time, for nasal foreign bodies, unilateral purulent rhinorrhea may develop with a foul odor and epistaxis [15]. The nature of the foreign bodies was variable and diverse. In our study, we noticed a predominance of inorganic foreign bodies as in Tall's study [10]. A case of button cell battery was observed at the nasal level. Button cells are a special case, particularly dangerous, and the cause of serious lesions (mucosal ulcerations are almost systematic) [16]. More and more devices for daily use, within reach of children in homes, use this type of battery, thus increasing the risk of ingestion [4]. Esophageal, pharyngeal and bronchial foreign bodies; together with nasal foreign bodies constitute the foreign bodies of the aero-digestive tract. Two cases were observed for each without complications. The diagnosis of foreign bodies can sometimes be easy [12]. Symptoms and diagnostic methods depend on the site [11]. Indeed, those of the nose and pharynx can be revealed by careful clinical examination, as some authors attest [12]. The penetration syndrome directs towards a foreign body of the laryngotracheobronchial pathway. In some cases, radiography is important in the diagnostic approach. However, the absence of radiological signs should not reject the diagnosis of foreign bodies [3]. Dysphagia and hypersialorrhea can direct to foreign bodies in the esophagus or pharynx $[11,17]$. In the present study, the $x$-ray diagnosed foreign bodies in the esophagus and bronchi.

\subsection{Therapeutic Aspects}

The extraction was carried out by natural means according to the principle of Chevalier Jackson, who said in 1951: "Any foreign body of the digestive or airways which has entered through the digestive or airways must be extracted by the same routes provided that 'it did not migrate through the perforated wall of these pathways" [18, 19]. Exceptions to this rule had to be transferred so were not included in this study. Extraction is often done without or under local anesthesia by the introduction routes, under visual guidance with a Clar mirror, using a microscope or rigid or flexible endoscopy. The use of specific forceps for extraction is the most widely used technique. The use of general anesthesia for the extraction of foreign bodies in the literature varies between $8.6 \%$ and $30 \%$ of cases [2]. In the present study, general anesthesia was only used in esophageal and bronchial foreign bodies removal representing thus 4 cases $(5.88 \%)$. Complications from foreign bodies in the ENT sphere can be serious, such as obstruction of the upper respiratory tract leading to suffocation, visceral perforations and serious infections (mediastinitis, pneumonia) [2, 20]. We have not recorded any cases, but in the literature its rate can reach $22 \%[1,2]$.

\section{Conclusion}

Foreign bodies in ENT, represent a pathology of importance because of its frequency and its potential severity. Auricular and nasal locations are more frequent. These accidents occur in the vast majority of cases in little boys. It seems essential to us to consider this problem of foreign bodies from the angle of prevention by a real education of parents on the choice of toys and objects made available to children. The enhancement of the technical platform of peripheral health structures is necessary to relieve congestion in hospitals allowing prompt treatment and care.

\section{Declaration of Interests}

The authors declare that they have no conflicts of interest for this case study.

\section{References}

[1] Hssaine K., Belhoucha B., Rochdi Y., Nouri H., Aderdour L., Raji A. Foreign bodies in ENT: ten years' experience. Pan African Med J 2015; 21 (91): 1-6.

[2] Diallo AO., Keita A., Itiere Odzili F A., Diallo OA., Fofana M., Conde B., Diallo MT., Diallo MMR. Foreign Bodies in Otorhino-Laryngology: Analysis of 192 Cases at the University Hospital Center of Conakry. Health Sci. Dis: 2018; 19 (2): 61-65. 
[3] Kacouchia N., N'gattia K V., Kouassi M., Yoda M., Buraima F., Tanon-Anoh M-J., Kouassi B. Foreign bodies of the upper airways and digestive tracts in children. Rev. Col. OdontoStomatol. Afr. Chir. Maxillo-fac. 2006; 13 (3): 35-9.

[4] Lahmar J J., Célerier C., Garabédian EN., Couloigner V., Leboulanger N., Denoyelle F. Esophageal lesions following button-battery ingestion in children: Analysis of causes and proposals for preventive measures. Eur Ann Otorhinolaryngol Head Neck Dis 2018; 135 (2): 91-4.

[5] Kharoubi S. Foreign bodies of the nasal cavities: study of 700 cases and review of the literature. Journal of Pediatrics and Childcare 2010; 23: 314-21.

[6] Doumbia Singare K., Timbo S. K., Kéïta M., Togola-Konipo F., Guindo B., Soumaoro S., Ag Mohamed A. Foreign body of the esophagus in adults: about 26 cases. Mali Med 2011; 26 (3): 1-4.

[7] Samaké D., Sidibé Y., Thiocary S., Koné F. I., Maïga Y. M., Konaté F., Dara Y., Singaré K., Haidara A. W., Dembele A., Sacko D., Traoré M., Sanogo B., Timbo S. K., Kéita M. A., Ag Mohamed., A. Place of Otorhinolaryngological (ENT) Diseases in a $2^{\text {nd }}$ Level Health Center: Case of the of Commune V (CSRéf CV) Reference Health Center of the District of Bamako. International Journal of Otolaryngology and Head \& Neck Surgery 2019; 8, 91-97.

[8] N'jiffou Njimaa A., Ndjock R., Essama L., Moby H., Fonyam V., Bitang L J., Zambo Oyono J C., N'Djolo A., Ebana Mvogo C. Profile of ENT pathology at Laquinitinie Hospital in Douala. Medicine from black Africa. 2013; 60 (10): 415-18.

[9] Ouoba K., Dao O M., Elola A., Ouedraogo I., Gyebre Y., Ouedraogo B., Bationo E. ENT emergencies at the Ouagadougou University Hospital Center: about 124 cases. Black African medicine 2006; 53 (4): 241-46.

[10] Tall H., Dembélé A., Touré A Y F., Faye N D., Ndiaye M., Diallo B K. ENT foreign bodies in children: about 95 cases. Tunisian ENT Journal 2016; 35: 22-4.

[11] Lawson STLA., Asoumah KD., Ayena KD., Amana B., Boko E., Kpemissi E. Foreign bodies in Otorhinolaryngology at Kara University Hospital. Black African Medicine 2010; 57: 461-65.
[12] Calmels M N., Bergès C. Foreign bodies in children in otolaryngology. Pediatric Archive 2009; 16: 956-58.

[13] Ray R., Dutta M., Mukherjee M., Gayen GC. Foreign bodies in the Ear, Nose and Throat: Experience in a Tertiary Hospital. Indian J Otorhinologol Head Neck Surg 2014; 66 (1): 13-16.

[14] Eziyi Josephine Adetinuola E., Uchendu Chukwuemeka D., Olusoga-Peters Oluwapelumi O., Ikoko M., Ameye Sanyaolu A. Foreign bodies in the ear, nose and throat: clinical profiles from a nigerian tertiary hospital. European journal of pharmaceutical and medical research 2018; 5 (3): 538-43.

[15] Yaroko AA., Baharudin A. Patterns of nasal foreign body in northeast Malaysia: A five-year experience. Eur Ann Otorhinolaryngol Head Neck Dis 2015; 132 (5): 257-59.

[16] Abou-elfadl M., Horra A., Abada R L., Mahtar M., Roubal M., Kadiri F. Nasal foreign bodies: Results of a study of 260 cases. Eur Ann Otorhinolaryngol Head Neck Dis 2015 (6); 132: 34346.

[17] Bouraïma F A., Hounkpatin SHR., Flatin M C., Sake K., Avakoudjo F., Akanni D., Deffo H N., Adjibabi W. Management of foreign bodies in children's upper digestive tract at Parakou, Benin. Journal of Otolaryngology-ENT Research 2019; 11 (6): 261-264.

[18] Nyeki AR., Miloundja J., Dalil AB., Lawson JM., Nzenze S., Sougou E., Nziengui A., N'zouba L. Laryngotracheobronchial foreign bodies: Experience of the army training hospital Omar Bongo Ondimba (HIAOBO) de Libreville. Pan Afr Med J. 2015; 20: 298.

[19] Maïga S., Barry MW., Diom ES., Ndiaye C., Diouf M S., Deguenonvo R E A., Palou E R J., Ndiaye M., Ndiaye I C., Diouf R. Laryngotracheobronchial foreign bodies: about 130 cases. Black African Medicine 2016; 63 (12): 629-34.

[20] Diouf-Ba MS., Ndiaye M., Deguenonvo R., Thiam A., Traoré MM., Touré S., Tall A., Diallo BK., Ndiaye IC., Diouf R., Diop EM. Mortality in children with foreign bodies of the lower respiratory tract. Experience in the ENT department at Aristide Le Dentec Hospital. Black African Medicine. 2014; 61 (7): 368-72. 